\title{
When you ask the fish: Child wellbeing through the eyes of Samoan children
}

\author{
Emma Dunlop-Bennett · Jenny Bryant-Tokalau · Anthony Dowell
}

\begin{abstract}
Child wellbeing is the subject of substantial academic and policy interest globally and in New Zealand. Notably however, the voices of children are largely missing in much of the extended literature. In addition, and largely due to an assumption that wellbeing is a universally held construct, the influence of cultural values and beliefs on the perceptions and experiences of wellbeing of children, such as the Samoan children in this study, have not warranted in-depth attention. This study explores the influence of culture on how 8-year old Samoan children living in Wellington, NZ, conceptualise their wellbeing (Dunlop-Bennett, 2019). Part I of this article details the research approach developed for this study. Guided by Talanoa ile i'a (Faleolo, 2009) or 'Talking to the Fish', this study positioned children as experts on their wellbeing and through the use of talanoa and photos successfully created the reflective discussion space for 11 Samoan children to share their knowledge. The findings, outlined in Part II, show that when given the opportunity, these Samoan children offered critical and realistic insights into their experiences and aspirations. One model of wellbeing shared by these children used the analogy of a seesaw, where wellbeing was achieved when the "good bits and the bad bits" are balanced. The influence of context of wellbeing was a second key finding. These Samoan children's experiences of wellbeing indicated a subtle interplay and balancing of their fa'asamoa (the Samoan way) and New Zealand life experiences. While this ethnic-specific study does not purport to represent the diversity of the Samoan diaspora, it presents a model that can be adapted by the Samoan diaspora living in other parts of New Zealand as well as other Pasifika and minority groups, as appropriate.
\end{abstract}

Keywords: Child wellbeing, Samoan wellbeing, culture, wellbeing

\section{Introduction}

Child wellbeing is the subject of a substantial body of academic and policy interest. Its significance is reflected in international consensus in agreements such as the United Nations Convention on the Rights of the Child (UNGA, 1989) where 195 countries including New Zealand have agreed that every child has the right to wellbeing. The World Summit for Children (UNGA, 1990) and more recently the 2030 Agenda for Sustainable Development (UNGA, 2015) have emphasised the importance of child wellbeing to a country's social, economic and environmental development. The early years of a child's life are particularly important because it lays the foundations on which "virtually every aspect of human 
development - physical, intellectual and emotional - are laid down" (Marmot, 2010, p.16). Investing in children from an early age not only lays the foundations for better outcomes, it can also mitigate the negative effects of poverty that lead to poor health, low educational attainment, economic dependency, gender inequality, and increased violence (Heckman 2008; Naudeau, Kataoka, Valerio, Neuman, \& Elder, 2011; Neuman \& Devercelli, 2013).

The way in which child wellbeing is used in the literature suggests that the concept has a shared meaning, however this is not the case (Amerijckx \& Humblet, 2013; Ben-Arieh, 2000; Ben-Arieh, 2008; Ben-Arieh, Ferran, Frønes, \& Korbin, 2014; Cronin de Chavez, BackettMilburn, Parry, \& Platt, 2005; Ereaut \& Whiting, 2008; Pollard \& Lee, 2003; Statham \& Chase, 2010). As Ereaut and Whiting (2008, p.5) explain, “...different meanings are being projected by different agents and what is apparently meant by the use of the term depends on where you stand. There are few fixed points or commonalities beyond 'it's a good thing' ".

The term child wellbeing is used differently across disciplines and across diverse social cultural contexts which are, in turn prone to change. Reaching a shared definition and understanding of child wellbeing is challenging because how it is conceptualised depends on where one stands culturally and socially. Child wellbeing is defined, conceptualised, and referred to in so many ways that it has led to some questioning its value (Seedhouse, 1995). Fattore, Mason, and Watson (2016, p.v) capture this when, at their long list of child wellbeing dimensions, they say, “...- in short, almost every possible theme can be related to well-being".

While there is a substantial body of academic and policy literature on child wellbeing, little of it is from the perspective of children. Despite children being able to offer authoritative knowledge of their world and their experiences, their voices have largely been missing in research about their wellbeing (Ben Arieh, 2001; Ben Arieh, et al., 2014; Fattore, et al., 2007, 2009, 2016; Prout \& James, 1997; Sixsmith, Gabhainn, Flemming, \& O’Higgins, 2007). Much of what we know about the wellbeing of children is through the perspective of adults, which may not necessarily reflect the views of children. Further, while our understanding of child wellbeing is influenced by where we stand culturally and socially, little of the extant literature recognises the influence of other worldviews, cultural beliefs and values, and ways of knowing. Much of the child wellbeing literature focuses on children predominately in North America, Europe, and other Western countries, which may have little relevance for children living in other socio-cultural contexts (Amerijckx \& Humblet, 2013; Camfield, Streuli, \& Woodhead, 2010; Ben-Arieh, et al., 2014; Fattore, et al., 2016; Manolom \& Promphakping, 2015; Saith \& Wazair, 2010; Weisner, 2014; White, 2009).

This article draws on an exploratory study of how Samoan children living in Wellington conceptualise their wellbeing (Dunlop-Bennett, 2019). The starting position of this study was that if it is to be credible and of value, it needed to ask those that know, live, and breathe the phenomena. For research on child wellbeing, those who know are the children themselves. Given the paucity of literature from the perspective of peoples outside of the mainstream, this 
study initially focussed on Pasifika which, in talking with community leaders from the Pasifika community, was refined to take an ethnic-specific focus on the Samoan diaspora.

The aims of this article are two-fold. Having established that research on child wellbeing needs to privilege the voices of the children themselves, Part I details the innovative research approach that was developed to create the space for Samoan children to be share their insights. Involving children in research is challenging given that in most cases, as seen in the literature, they are often not asked. This is particularly challenging for children who are raised in cultures where to a large extent they are 'seen but not heard'. Involving 8-year old Samoan children in research required a process that was not only child friendly and age appropriate but also culturally authentic. This saw a weaving together of research methods grounded in the fa'asamoa (the Samoan way) and fa'apalagi (the non-Samoan way). Part II of this article highlights the findings that emerged from applying this innovative research approach. Samoan children were able to conceptualised their wellbeing and articulate what was important to their wellbeing. The findings are followed by a discussion of the significance of this study. To set the context, a brief overview of Pasifika is provided.

\section{Pasifika peoples in New Zealand}

Pasifika is the collective term used to refer to people who have migrated from the Pacific - a region comprising 22 countries and territories - or who identify as Pasifika through descent. At the 2013 census, ${ }^{1}$ Pasifika was the fourth largest peoples in New Zealand. Pasifika made up 13 percent of all children in New Zealand under the age of 18 years (OCC, 2016) and accounted for 12 percent of all births in New Zealand (Pool \& Jackson, 2017), yet there has no research on how Pasifika children conceptualise their wellbeing. With one in every five school children projected to be of Pasifika ethnicity by 2051 (Ferguson, Gorinski, Wendt Samu, \& Mara, 2008), it makes good sense - from a practical and best practice point of view - to include the voices of Pasifika in child wellbeing research, policy, and programming.

Pasifika are often portrayed in New Zealand as hard-to-reach, vulnerable, and disengaged (Loto, Hodgetts, Chamberlain, Nikora, Karapu, et al., 2006; Neilson, 2015). This deficit view does not reflect the way Pasifika view themselves nor the aspirations that they hold for their children, families, and communities, as Percival (NZCYES, 2008, p.24) explains: "Nothing matters more to Pacific people than the health, well-being and future success of our children. Our community's future is inextricably linked to their health and success". This disconnect between how Pasifika are portrayed and how they would portray themselves highlights very compellingly the need to explore how Pasifika children, from their standpoint, conceptualise well-being.

\footnotetext{
${ }^{1}$ This article uses data from the 2013 Census of Population and Dwellings as only limited data from the 2018 census has been released. Unless specified, all population data is from

Statistics New Zealand website: www.stats, govt.nz.
} 
As noted, Pasifika does not refer to a single ethnicity or nationality. While there are some similarities amongst the ethnic groups covered by this collective term, each ethnic group has its own set of cultural beliefs, values, traditions, language, and social structures (Macpherson, 1996; Anae, Coxon, Mara, Wendt-Samu, \& Finau, 2001). Anae (2010, p.1) has questioned the value of most Pasifika research because it has “... 'glossed over' and ignored the cultural complexities of not only the multi-ethnic nature of Pacific communities but also the intra-ethnic nuances of the diverse groupings and identifies of Pacific peoples in New Zealand". To reflect the multi-ethnic nature of Pasifika and to capture the intra-ethnic nuances that exist within the ethnic groups that make up the Pasifika collective term, this study took an ethnic-specific approach. It focussed on the Samoan diaspora, which is the largest Pasifika ethnic group comprising 48.7 percent of the total Pasifika population.

The Samoan diaspora is diverse and becoming increasingly so, shaped by the many different lived experiences in the diaspora, intergenerational differences, and new forms of Samoan identity that are emerging as they make their place in New Zealand. With 62.7 percent $(89,271$ people) of the Samoan diaspora being born in New Zealand, the story has shifted from a 'migrant story' to one in which 'New Zealand is home'. Samoans living in New Zealand, like other diasporic communities, are constantly navigating between different cultural worlds - the $f a^{\prime}$ asamoa and fa'apalagi worlds - and across spectrums of segregation, accommodation, and integration with the dominant New Zealand society (Berry, 2006). Like all cultural ideals and practices, the fa'asamoa has adapted and continues to adapt to shifts in the broader social and economic contexts (Anae, 2001; Cowley, 2013; Lilomaiava-Doktor, 2009; Mageo, 1998). The influence of these broader contexts have led to some arguing that the fa'asamoa should be renamed the fa'aaukilani or the fa'auelitone to account for the unique way in which it is being adapted in Auckland and Wellington (Macpherson, 1997; Taule'ale'ausumai, 1990). To reflect the influence of the broader contexts, this study focussed on the Samoan diaspora living in Wellington. In 2013, the Samoan diaspora living in Wellington comprised 22,383 people of which 44.9 percent $(10,041$ people) were under the age of 19 years.

Having set the study context, this article details how the space was created for 8-year old Samoan children to share their knowledge and experiences in research.

\section{Part I: Creating the space to talk to the fish}

It was clear from the outset of this study on child wellbeing that if the findings were to be credible and of value, it needed to include the voices of Samoan children. What was less clear was how to design the research approach to enable this. Including children in research can be challenging. There is a view that children lack research competence, they are not capable of articulating their views clearly, and that the power differential makes it uncomfortable for them to share their views with an adult researcher (Bradbury-Jones \& Taylor, 2013). As participatory research with children becomes more frequent, there is a growing body of literature about how to include young children in research in a way that makes them feel comfortable and that their contribution matters (see: Bradbury-Jones \& Taylor 2013; Graham, Powell, Taylor, Anderson, \& Fitzgerald, 2013; O’Reilly \& Dogra, 2017). 
There is less guidance on how to include Samoan children, or Pasifika children more broadly, in research. A key challenge of this study was how to design it so that it was not only child friendly and age-appropriate but that it was culturally authentic. The study needed to be grounded in the Samoan worldview but also reflect the diversity that exists within the Samoan diaspora and the constant moving between the fa'asamoa and the fa'apalagi, which marks the daily lives of many Samoan children. This required ongoing review of the literature on Pasifika, the Samoan diaspora in New Zealand, participatory research with children, customary child raising ideology and practice amongst other ethnic minority diaspora groups, and piloting different methods with the Samoan diaspora. This review, piloting and rethinking saw a weaving together of research methods grounded in the fa'asamoa and the fa'apalagi. To help explain why this was needed, the next section highlights how knowledge is constructed in the Samoan worldview and place of children in this.

\section{The place of children and knowledge construction in the Samoan worldview}

While the fa'asamoa is adapting, generally the Samoan worldview is communal and family based, with prominence given to the collective. Samoans do not stand alone as individuals but in relationship with their aiga or family (Seiuli, 2012; Tamasese, Peteru, Waldergrave, \& Bush, 2005; Tui Atua, 2003). This concept is captured in the Fonofale (Pulotu-Endermann, 1995) in which a fale or house is used to illustrate wellbeing. The foundation of the fale represents family while the roof symbolises cultural values and beliefs. The inference is that the individual does not stand alone but is grounded in the family, which is in turn sheltered by cultural values and beliefs (Fairbairn-Dunlop, Nanai, \& Ahio, 2014). While the Fonofale does not reference Samoan children, these ideas extend to them. Samoan children are raised to know their place in relation to family, as Cowley-Malcolm, Fairbairn-Dunlop, Paterson, Wanzhen, and Maynard (2009, p.27) explain, "Children are raised to know their roles, to act on them diligently in the 'service' or tautua to their 'aiga'. They know where to speak and not to speak, how to look and not to look, who to speak to and not to speak, how to address and not address."

Samoan children are raised to have amio lelei (good behaviour), which amongst other expectations such as studying hard at school and coming home straight after school so they can help with household chores, is the expectation that they will listen and obey their elders (Cowley-Malcolm, et al., 2009; Pereira, 2012; Schoeffel, Meleisea, David, Kalauni, Kalolo, et al.,1996). Generally speaking, it is often said that Samoan children are raised to be seen and not heard.

Looking at how knowledge is constructed, value is placed on the wisdom of the collective and the importance of communally agreed-to decision-making systems and processes (Anae, et al., 2001; Fairbairn-Dunlop, et al., 2014). Children - as is common in gerontocracies in which 'wisdom' and 'knowledge' is correlated with age - tend not to be included. Tui Atua (cited in Tamasese, Peteru, Waldegrave, \& Bush, 2005, p.301) describes Samoan knowledge constructive processes as bringing together three perspectives: 
In Samoan culture, there are three perspectives. The perspective of the person at the top of the mountain, the perspective of the person at the top of the tree, and the perspective of the person in the canoe who is close to the fish. In any big problem, the three perspectives are equally necessary. The person fishing in the canoe may not have the long view of the person at the top of the tree, but they are closer to the school of fish.

As seen in this parable, the school of fish or the children have no voice but rather their perspective is given by those fishing in the canoe such as the parents or other elders: a perspective which could be distorted by the refraction of the sea.

Building on this parable, Faleolo (2009) argues that if we really want to know what is important to the fish, we need to talk to the fish. In Talanoa ile i'a, Faleolo (2013, p.118) writes that including the perspective of the fish is about "... honouring and creating a pathway for the lesser known to become known, acknowledged and institutionalised". Integral to Talanoa ile i'a is the talanoa or talk, which is done in such a way that it provides opportunities to probe, challenge, clarify and re-align the discussion (Vaioleti, 2006). As a concept, talanoa has resonance across the Pacific but Vaioleti is credited as "adding to it a technical research-related meaning" so that it is not only simply about the 'talk' itself but also about the way in which the 'talk' is done" (Suaalii-Sauli \& Fulu-Aiolupotea, 2014, p.333). Fairbairn-Dunlop \& Coxon (2014) argue that talanoa supports the creation of 'safe places' where people can share their stories and share them in ways where their voices are privileged.

Talanoa ile i'a (Figure 1) provided the cultural frame to include the voices of Samoan children, while talanoa created a 'safe space' for Samoans to share their stories and experiences. This raised the question of how to adapt the talanoa process for children and ensure that they felt comfortable to share their ideas. The connecting piece was use of photography, which is positioned in the literature as a child-friendly way to engage with children. There are a number of ways in which photography can be used in research, from children being given a set of photos to choose from through to children taking photos of what they view as important to the topic. These ideas were piloted with two 8-year-old Samoan children who said they wanted to decide what photos they took. In response to the researcher's offer of a disposable camera, the children said that they did not know how to use it and that taking photos on a phone would be easier for them. In refining the research approach in line with this feedback, the researcher selected photovoice (Wang \& Burris, 1997) to help guide the talanoa with children 


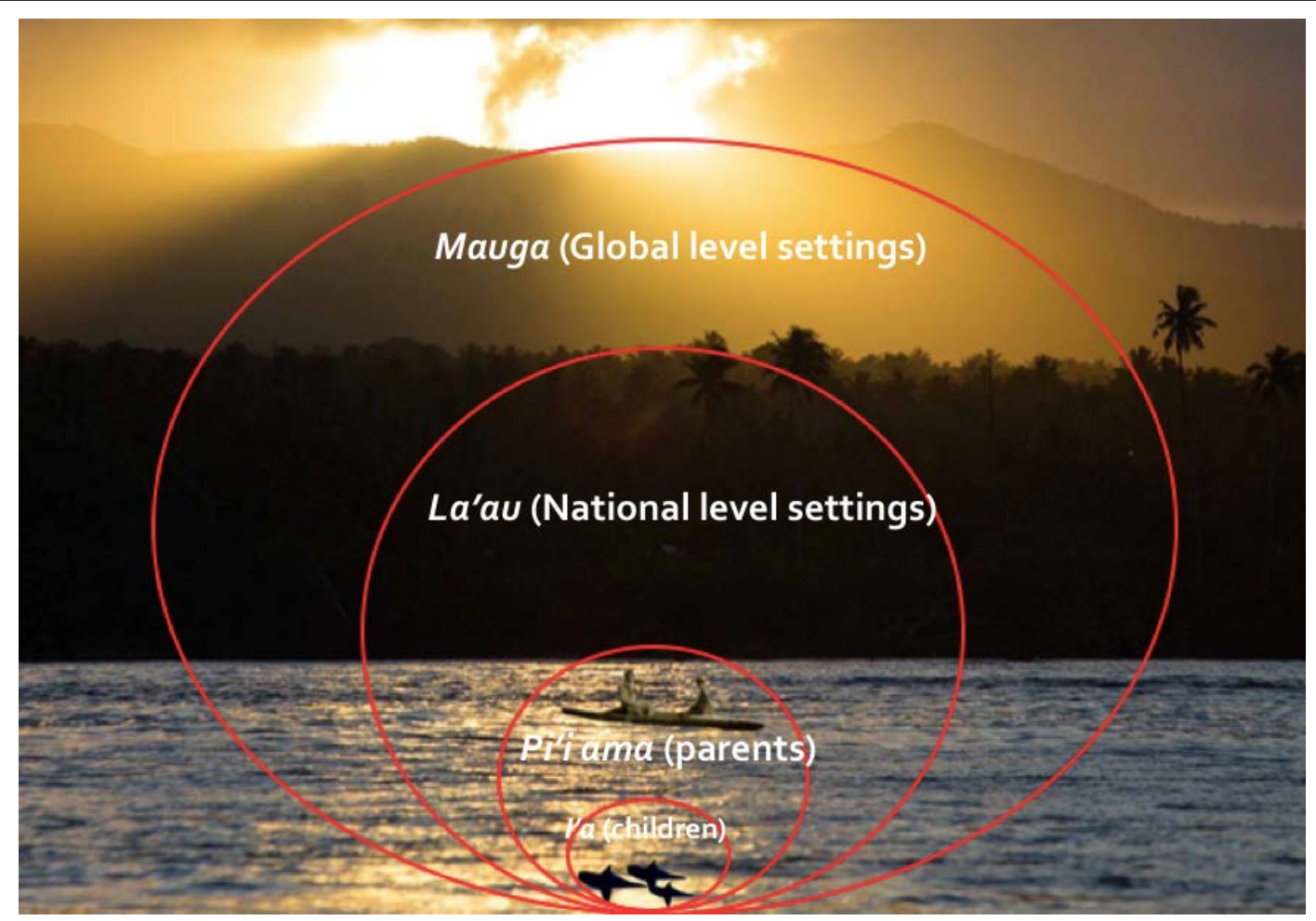

Figure 1: Talanoa ile i'a.

Source: Dunlop-Bennett adapted from Faleolo (2009).

Recruiting the fish and getting their consent

To recruit Samoan children to this study, the researcher used a respondent-driven sampling, in which as families were recruited they recommended other families. This approach was useful in reaching people beyond the researcher's social group (Ellard-Gray, Jeffrey, Choubak, \& Crann, 2015). To be eligible, the children needed to be:

1. Samoan to enable in-depth research that captures the intra-ethnic nuances within the Samoan diaspora, the largest Pasifika ethnicity in New Zealand;

2. 8-years old to reflect the importance of investing in the early years of a child's life. The global definition of ECD is children from birth to 8 years of age; and

3. Live in Wellington, which was selected to account for the influence of the broader context.

The researcher accepted the first five families who met the research criteria, and their children became Phase 1 participants. For Phase 2, the researcher targeted recruitment to allow for gender balance, representation across the Wellington region, ${ }^{2}$ and inclusion of a child living with a disability. Sixteen families expressed interest in participating in this study of which 10 were selected. It was intended that one child from each family would share their insights on what child wellbeing meant to them, but this increased to 11 children to account for one set of twins. Annex 1 shows the profiles of the Samoan children and their parents.

\footnotetext{
${ }^{2}$ About 80 percent of the Wellington Region live in Wellington City, Porirua and the Hutt (Lower and Upper Hutt. Porirua and the Hutt are both located about 20 kilometres from Wellington City.
} 
In terms of consent, Suaalii and Mavoa (2001) argue that for Pasifika knowledge is measina (treasure) and Pasifika children may not have the right to share this treasure without the consent of other family and community members. Guided by this, as well as the researcher's own cultural frame as a Samoan, a two-step consent process was used in recognition of the collective nature of the fa'asamoa where children's identity and voice are closely bound within family and community contexts. Parents of eligible children were asked for their consent, before the researcher approached the children for their consent. ${ }^{3}$

\section{Talking with the fish}

Based on the pilot phase, photovoice (Wang \& Burris, 1997) was selected in which the Samoan children took photos of anything that best told their story from their perspective. As wellbeing is not a term that is used in the everyday language of young children, the Samoan children were asked to take 10 photos of what makes them feel 'happy, safe, and loved'. These descriptors of wellbeing were intentionally kept short so that it was easy for the children to remember. Over the research process, these descriptors were used by the researcher and the children as an anchor for the concept of wellbeing. The second stage of photovoice is contextualising the photos through discussion or talanoa, which Wang and Burris (1997, p.381) argue is important because, "Photographs alone, considered outside the context of [their] own voices and stories, would contradict the essence of photovoice".

The contextualising of photos by the children took place in a group-setting or fono ${ }^{4}$ which reflects the communal knowledge construction and validating processes integral to the Samoan worldview. The group-setting approach of a fono can mask dissenting opinions, as people converge around a 'norm' which sees those who sense that their original ideas are not shared, abandon these in favour of more widely-shared views. While cognisant of this, the researcher selected the group-setting approach to help the 8-year old children feel at ease with the research process and comfortable to share their views. The researcher sought to mitigate the influence of group-think through the approach taken during the talanoaga ${ }^{5}$ as well as the analysis of the talanoa, which is discussed later in this section. Figure 2 provides an overview of how the children were involved in this study.

\footnotetext{
${ }^{3}$ Parents of the Samoan children also participated in this study through individual talanoaga with the researcher. The findings that emerged from the parent's talanoa can be found in -Bennett, E. (2019). Through their eyes: A Samoan perspective on child wellbeing [unpublished thesis]. Dunedin: University of Otago.

4 fono - a meeting or gathering to discuss issues

${ }^{5}$ talanoaga - a discussion
} 


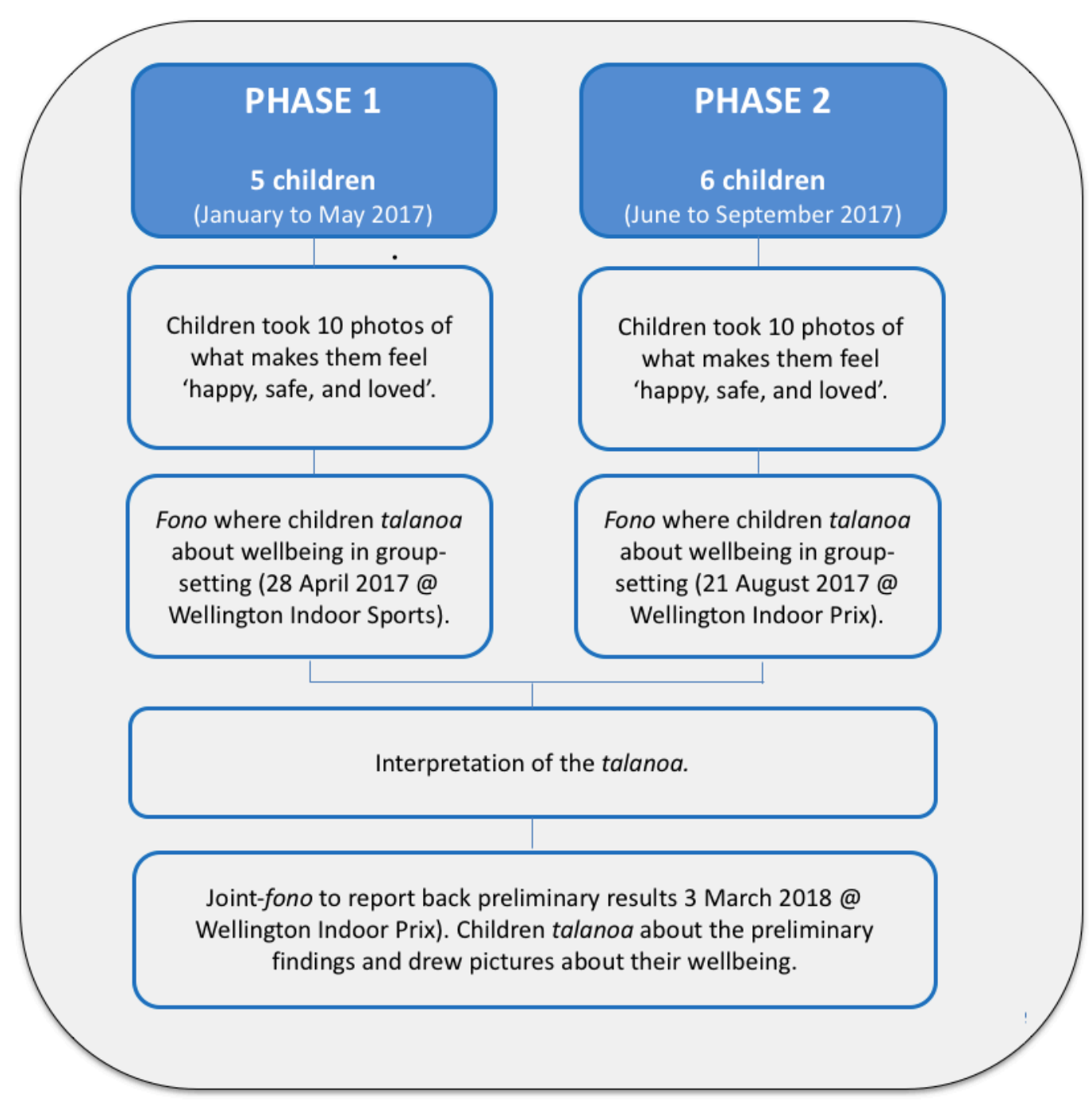

Figure 2: An overview of the methods used with the Samoan children.

The fono were designed to keep the children engaged, to ensure that they all participated, and that the talanoaga was age-appropriate. As the children were from different parts of Wellington and may not have known each other, the fono began with an activity to 'break the ice' including indoor bowling or go-karting. To help mitigate against children feeling that they needed to conform their answers, the researcher began each talanoaga along the following lines:

Researcher Before we start, there are just a couple of things. First of all...there are no wrong answers. Everything you say is right because it's important.

Tomasi ohhh that's cool.

Tavita I can do that.

Researcher If you don't want to answer a question, that's okay you don't have to just say pass.

Pele Say nothing.

Moana Or yes, don't say anything.

And if I've misunderstood you or you don't get something I say, just let me know. It's all good. And the last thing... it's okay if something you say [points to a child] is different to 
something you say [points to another child] because we all have different stories and that's what makes this so cool. Alright guys?

To keep the children engaged in the talanoaga, it was structured like a quiz game where the researcher asked questions like, "You have ten seconds to show me a photo of what makes you feel loved". Each child was given a hand-sized copy of their photos so that they could easily flick through them to find the one they wanted to support their talanoa. Once they had selected the photo, each child was given the opportunity to answer every question. As shown in the following excerpt the children's answers varied in length and in detail.

Researcher Okay now we are going to look for a photo.... have you all got your photos still? Great. You have 10 seconds to find a photo that makes you feel safe.... Okay who is going to go...ola you all want to go first (laughs)....Mosese, what photo have you chosen?

Mosese This is a photo of me looking after my cousin. We were at the waterfront... ummm on the ice and my cousin couldn't go by herself. She was too young... so there was a frame that she leant on and I helped her.

Researcher What a great big cousin you are. What is it about this photo that makes you feel safe?

Mosese Well my cousin felt safe cos she was with me. I feel safe when I'm with someone...you know, someone who is looking after me.

Researcher That's a really great answer. Thanks Mosese. Tualagi, what photo do you have there?

Tualagi I've got three photos (laughs).

Researcher (laughs) Great, which photo would you like to talk about first?

Tualagi This one. It's my bedroom...and it makes me feel safe because... I'm in a house that won't blow away.

Researcher That's great Tualagi.

Tualagi Also it has all my special things in it...like my toys and now I have a bunk bed... and I like being with my little lamb that makes noises.... Mata gave it to me before she died so.....

Researcher So that's really special then?

Tualagi Yeah.

Researcher That must have been sad?

Tualagi Yeah...my mum and dad say she's ok though...we know where she is.

Researcher Yes, your mum and dad are right. What is your other photo of?

Tualagi Oh this one...its popcorn.

Researcher (laughs) Popcorn?

Tualagi (laughs) Yeah...cos my sister makes it for me...it's my favourite snack.

Researcher What is it about your sister making you popcorn that makes you feel safe?

Tualagi Cos she looks after me...I'm safe with her...I like it when she looks after me...you know, if mum and dad are busy... I feel safe.

Researcher That's really great. And your last photo.

Tualagi It's this one...with my dad again.

Researcher In your onesie? 
Tualagi Yeah, I don't have a photo of my mum...I don't know why....cos my mum and dad make me feel safe all the time... they protect me and help me when I'm hurt....or when I'm sad they make me feel better...

While the group dynamic of the fono can add something extra to the talanoaga particularly for young children, it can also make it more difficult to develop personal phenomenological accounts (Palmer, Larkin, de Visser, \& Fadden, 2010; Phillips, Montaguea, \& Archer, 2016; Tonkin \& Eatough, 2010). Interpretive Phenomenological Analysis (IPA) was used to interpret the talanoa because it focusses on understanding not only an individual's lived experience but also how they make sense of their lived experience. Integral to this approach is 'giving voice' to the views of the research partners and 'making sense' of what is being said (Larkin \& Thompson, 2012; Larkin, Watts, \& Clifton, 2006; Smith, Flowers, \& Larkin, 2009). The presence of multiple voices - moving between individual and shared contexts, and the interactions between individuals - all add complexity to using IPA. To reflect the group setting of the fono, the researcher adapted the IPA by drawing out the voice of the individual fish from the school of fish. Guided by the literature (Palmer, et al.,2010; Phillips, et al., 2016; Tonkin \& Eatough, 2010), this was done by separating out each individual child's insights from the verbatim transcript of the fono and then selecting 10 blocks of talanoa for each child which reflected a particular point that they had made in relation to their wellbeing. The following excerpt is an example of one block of talanoa for Tasi, which was coded to the 'social connections/spending time with family' theme:

\section{Researcher Tasi, what photo have you chosen?}

Tasi This one. It's of playstation.

Researcher That's a great photo. What is it about your playstation that makes you feel loved?

Tasi Cos, my brother plays with me.

Researcher And that makes you feel loved?

Tasi Yeah, my brother always makes me happy.

Drawing out the voice of the individual fish from the school of fish helped to equalise the contribution made by each child, which was important because as shown earlier some children gave more detail in their answers while others gave less. Prior to doing this, the themes that emerged from the talanoa (Figure 3) gave the impression that they were of equal prominence. Overlaying the 10 blocks of talanoa for each child, shown as coloured circles, on top of the relevant theme totally changed the picture. In doing this, the most important theme, from the standpoint of the children, was 'not having to worry'. The most important sub-theme was 'spending time with family' under the 'social connections' theme, which accounted for 15 blocks of talanoa. This was the only sub-theme to be mentioned by all of the children. 
Theme 1: Wellbeing is a bunch of stuff

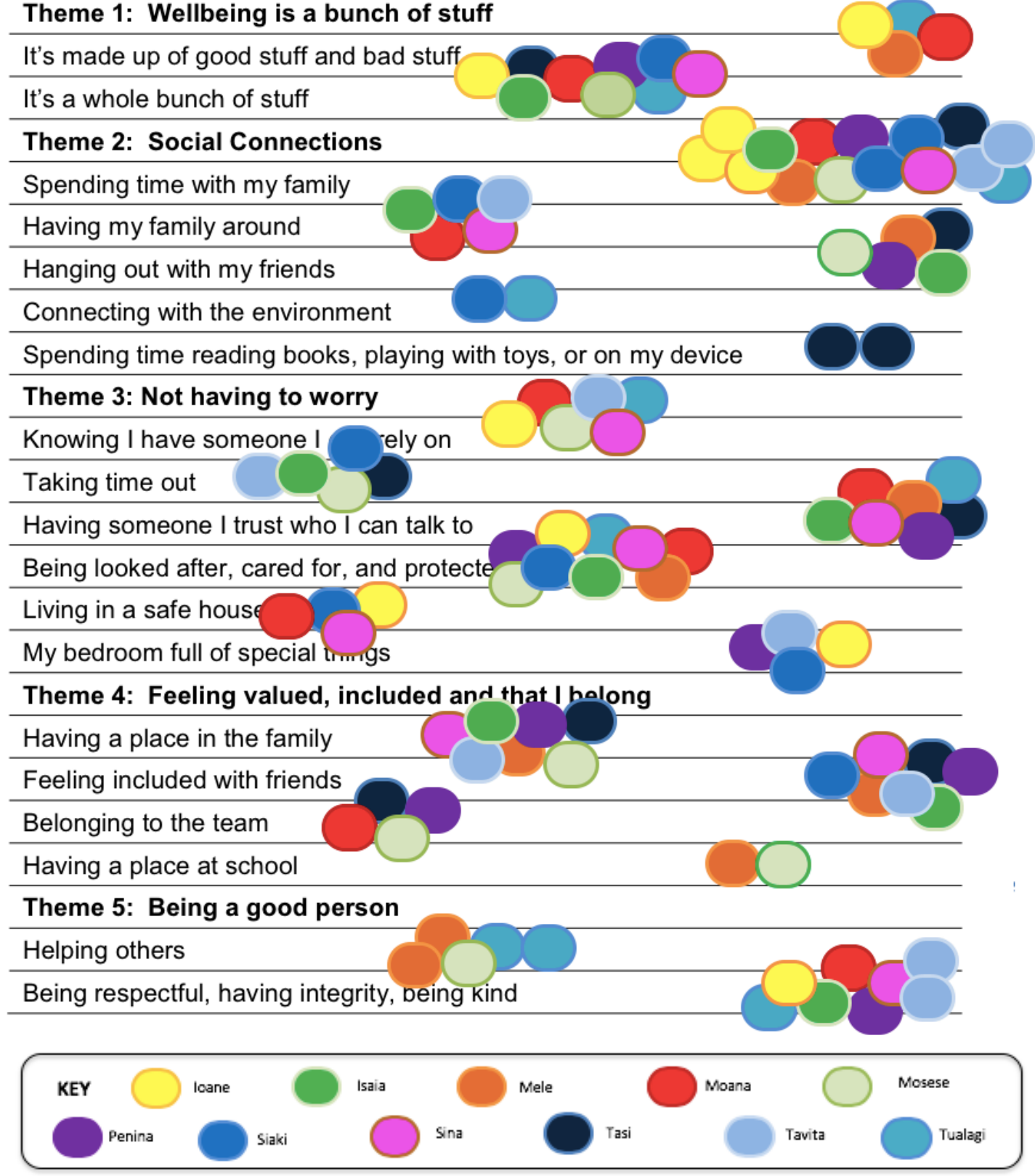

Figure 3: Drawing the individual fish from the school of fish.

To ensure that the children's voices were reflected accurately, they were invited to a joint-fono where the researcher discussed the preliminary findings with them. Of the 11 children who participated in Phase 1 and Phase 2, seven attended this report-back fono. During this joint-fono, almost all of the children drew pictures that illustrated how they conceptualised their wellbeing. These pictures included drawings of seesaws, flowers, treehouses, PlayStation, and iPads with apps. ${ }^{6}$

Part II: When you asking the fish - wellbeing through the eyes of Samoan children

\footnotetext{
${ }^{6} \mathrm{An}$ app is a piece of software that can be download to a device to look up information or to play a game (Reference: https://www.oxfordlearnersdictionaries.com/definition/english/app)
} 
Five themes emerged from the children's talanoa (see Table 1). The first theme related to how the children conceptualised wellbeing and the remaining four themes captured what they saw as important to their wellbeing.

Table 1

The key themes that emerged from the talanoa.

\begin{tabular}{|c|c|c|}
\hline Key theme & Description & Frequency \\
\hline \multirow{2}{*}{$\begin{array}{l}\text { Defining wellbeing } \\
\text { as a bunch of stuff }\end{array}$} & It's a bunch of stuff & 9 blocks of talanoa \\
\hline & It's made up of good bits and bad bits & 4 blocks of talanoa \\
\hline \multirow{5}{*}{$\begin{array}{l}\text { Connecting with } \\
\text { loved ones }\end{array}$} & Spending time with family & 15 blocks of talanoa \\
\hline & Having my family around & 5 blocks of talanoa \\
\hline & Hanging out with friends & 5 blocks of talanoa \\
\hline & Connecting with the environment & 2 blocks of talanoa \\
\hline & $\begin{array}{l}\text { Spending time reading books, playing with } \\
\text { toys, or on my device }\end{array}$ & 2 blocks of talanoa \\
\hline \multirow{6}{*}{$\begin{array}{l}\text { Not having to } \\
\text { worry }\end{array}$} & Knowing I have someone I can rely on & 6 blocks of talanoa \\
\hline & Taking time out & 5 blocks of talanoa \\
\hline & Having someone I trust who I can talk to & 7 blocks of talanoa \\
\hline & Being looked after, cared for, and protected & 9 blocks of talanoa \\
\hline & My bedroom full of special things & 4 blocks of talanoa \\
\hline & Living in a safe house & 4 blocks of talanoa \\
\hline \multirow{4}{*}{$\begin{array}{l}\text { Feeling valued, } \\
\text { included, and with } \\
\text { a sense of belonging }\end{array}$} & Having a place in the family & 7 blocks of talanoa \\
\hline & Feeling included with friends & 7 blocks of talanoa \\
\hline & Belonging to the team & 4 blocks of talanoa \\
\hline & Having a place at school & 2 blocks of talanoa \\
\hline \multirow[t]{2}{*}{ Being a good person } & Helping others & 5 blocks of talanoa \\
\hline & $\begin{array}{l}\text { Being respectful, having integrity, being kind, } \\
\text { and sharing }\end{array}$ & 8 blocks of talanoa \\
\hline
\end{tabular}

Looking at the first theme - how the children conceptualised wellbeing - in more detail, children described their wellbeing as a bunch of stuff (13 blocks of talanoa). This bunch of stuff included things which could be categorised as physical, socio-emotional, psychological, spiritual or cultural elements of wellbeing. For example, during the talanoaga the children spoke of playing sport and eating healthy food (physical); of unconditional love and not feeling lonely (socio-emotional); of talking to somebody they trust or people or taking time not having to worry about things (psychological); of praying when they were uncertain about something (spiritual); and of being proud to be Samoan (cultural). The ways in which the children spoke of what made them feel 'happy, safe, and loved' reinforced their holistic view of wellbeing. Several children spoke about wellbeing having good bits and bad bits, as illustrated in the talanoa shared by Moana: 
Researcher Oh, that's a clever way of putting it Moana. Can you tell me more about that?

Moana Well... like social media. It's good but then too much is bad.

Moana went on to talk about somebody dying, saying:

Moana If someone dies... well the good side is that they're in heaven...God is looking after them now. The bad side is that you don't get to spend time with them anymore.

Researcher You've explained that really well. So wellbeing is made up of good stuff and bad stuff?

Moana Yeah.

Tualagi also spoke of the contrasting positive and negative elements of wellbeing by likening wellbeing to a bumpy path of highs and lows. She said that the path was always going up and down, "so when it was low, it's ok cos it will go up again". At the joint-fono where the preliminary findings were shared with the children, the children agreed a definition of wellbeing that it was about "a bunch of stuff that has good bits and bad bits".

In terms of what was important to their wellbeing, four themes emerged from the talanoaga: 1) connecting with loved ones; 2) not having to worry; 3) feeling valued, included, and that they belong; and 4) being a good person. Table 2 provides one block of talanoa selected from the children to illustrate each theme. Looking across the four themes that emerged from what children viewed as important to their wellbeing, 87 of the 97 blocks of talanoa related to connecting with people and building relationships. This was integral to the children feeling 'happy, safe, and loved'. Connecting with people and building relationships made them feel valued, secure, and that they belonged. Only 10 of the 97 blocks of talanoa across these four themes related to material objects. This suggests that overall Samoan children conceptualise their wellbeing primarily in relational terms.

Table 2

What is important to the wellbeing of Samoan children?

\begin{tabular}{|l|l|}
\hline Theme & Children's talanoa \\
\hline $\begin{array}{l}\text { Connecting with } \\
\text { loved ones }\end{array}$ & $\begin{array}{l}\text { Ummm this one walking. I like doing hikes uphill... and the view [...] } \\
\text { Walking and stuff. Oh and I also like playing netball. This photo here } \\
\text { [...] I like playing netball because it makes me feel happy... even if we } \\
\text { lose, I like playing it. Also playing netball makes me fit, healthy. } \\
\text { Tualagi }\end{array}$ \\
\hline $\begin{array}{l}\text { Feeling secure and } \\
\text { not having to } \\
\text { worry }\end{array}$ & $\begin{array}{l}\text { This photo of my mum and dad is because they make me feel } \\
\text { safe...they look after me and help me and make sure I'm okay and care } \\
\text { for me...so it's okay... I know everything is okay... you know even if } \\
\text { I'm sad or something like that. Moana }\end{array}$ \\
\hline
\end{tabular}




\begin{tabular}{|l|l|}
\hline $\begin{array}{l}\text { Being valued, } \\
\text { feeling included } \\
\text { and that we belong }\end{array}$ & $\begin{array}{l}\text { [Speaking about somebody who is sad] If he had friends, he would be } \\
\text { happier. So we could try and be a friend [...] yeah, cos then he } \\
\text { wouldn't be lonely. There was someone at school who was lonely and } \\
\text { so we showed friendship. Penina }\end{array}$ \\
\hline $\begin{array}{l}\text { Being a good } \\
\text { person }\end{array}$ & $\begin{array}{l}\text { I'm learning how to help people and how to be nice to people [...] } \\
\text { Helping people is good to do. Mele }\end{array}$ \\
\hline
\end{tabular}

This study did not set out to develop a model to illustrate wellbeing from the standpoint of Samoan children, but the lack of children's voices in the literature meant that current models of wellbeing on offer did not fit with the insights that they shared. Finding a model that captured all of the children's ideas generated a lot of discussion at the joint-fono because of the number of ways in which the children illustrated their wellbeing, such as seesaws, flowers, treehouses, PlayStation, and iPads with apps. One of the ideas that resonated with most of the children was a seesaw, in which wellbeing is achieved when the "good bits and the bad bits" are balanced (Figure 4). The children spoke of the seesaw always moving up and down, which supports the dynamic nature of wellbeing. Knowing that the seesaw was always moving between good bits and bad bits was how the children viewed resilience.

Describing wellbeing as a "bunch of stuff" showed that the children viewed wellbeing as holistic concept. This "bunch of stuff" included that could be categorised as physical, socioemotional, psychological, spiritual or cultural dimensions of wellbeing, and is depicted by apps that represent these different dimensions. The use of apps by the children reflects their modernity while the placing of these apps within a box symbolises their holistic view of wellbeing. The children captured the relational aspect of wellbeing by positioning the seesaw in a park. In other words, the seesaw (a child) is surrounded by their parents, sisters and brothers, grandparents, aunties and uncles, cousins, and friends. 


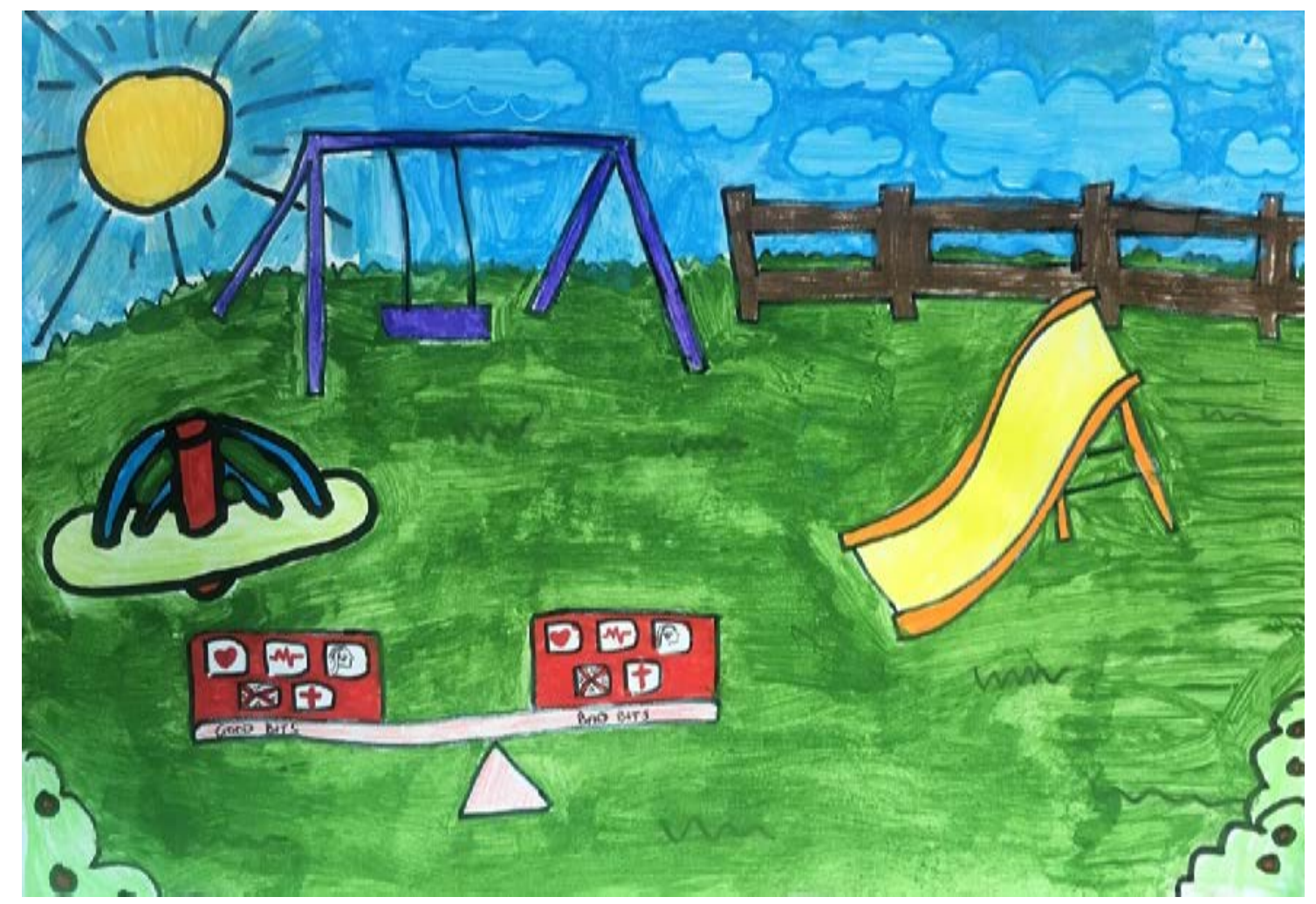

Figure 4: Wellbeing - a balance of good bits and bad bits.

Source: artwork by an 8-year old Samoan child.

\section{When you ask the fish and listen to their answers}

This study is an invaluable first step in understanding how 8-year old Samoan children living in Wellington conceptualise child wellbeing. The findings that emerged from this study moved beyond the contexts of the existing literature by an adding an original contribution to the discussion on child wellbeing. This is achieved by offering a new way to involve children, outside of the mainstream, in research and by adding new knowledge of how Samoan children living in Wellington conceptualise their wellbeing. Both of which are discussed in this section.

\section{The significance of the research approach}

Two points mark the significance of the research process. Firstly, this study reinforced the value of including children in research on issues that involve them. This study demonstrated that if research is to be credible and of, it must include the voices of those that know, live, and breathe the phenomena'. Using a model grounded in a Samoan worldview created the cultural space for Samoan children to be positioned as experts on their wellbeing and to have their views contributing to the generation of new knowledge. Research with children is often described as being difficult, with children positioned as 'incapable' of clearly articulating their view. This research has demonstrated that when given the opportunity, Samoan children have a view and are capable, interested, and eager to share their insights and offer valuable knowledge about their wellbeing. 
Secondly this study showed how research approaches grounded in the fa'asamoa and fa'apalagi could be weaved together to create the space for Samoan children to be included in research. Developing the research design was challenging because the process needed to be culturally and age appropriate to the Samoan worldview, as well as be sufficiently flexible to understand and take account of the changing times. This saw the weaving of fa'asamoa and fa'apalagi research methods such as: 1) Talanoa ile i'a which recognises and gives prominence to the children's voice; 2) the cultural concept and practice of talanoa which creates the safe space for children to share their stories; 3) group-setting talanoaga through fono; 4) the use of photography as a vehicle by which children could support their views, and 5) analysis of the children's insights through adapting the IPA to draw out the individual voice of each fish from the school of fish.

Bringing together research methods grounded in the fa'asamoa and fa'apalagi helped the children provide their insights in a meaningful way. The children said that taking photos and talking about what made them feel 'happy, safe, and loved' was fun. Being at ease and comfortable with the research process also helped the children share their views on sensitive issues such as feeling left out, feeling uncertain, and/or feeling sad. The topic of death for instance, which came up several times, was introduced by the children themselves. The talanoa shared by the children gave them a "shared ownership over the direction and focus of the discourse" (Fa'afoi, Parkhill, \& Fletcher, 2006, p.105). The benefits to children being invited to share their views, to have their views listened to, and to see their views clearly in the findings are immeasurable, as the children involved in this study themselves noted.

\section{The significance of the children's insights}

The cultural voices identified in this research have been notably missing in much of the child wellbeing research and debate, which has tended to assume a universal child wellbeing experience and in turn to suggest universal solutions. Developing solutions that are relevant and of value to the child wellbeing agenda in New Zealand begins with building knowledge and understanding about how children, including children outside of the mainstream, conceptualise their wellbeing. The significance of the children's insights can be distilled into three key areas. Firstly, it extends the current literature by offering a definition of child wellbeing from the perspective of Samoan children living in the diaspora. The children were able to conceptualise the complexity of wellbeing in a definition that makes sense to them. They defined wellbeing as "a bunch of stuff with good bits and bad bits". In defining their wellbeing in this way, the children understood the concept to be holistic and comprising of multiple dimensions. Further, they conceptualised that wellbeing being a balancing of the "good bits and bad bits". Defining child wellbeing in this way contributes new knowledge to the international literature. This definition, and how the Samoan children conceptualised wellbeing as a seesaw, is broad enough to "enable people to describe wellbeing in a way that fits with their culture, values, and priorities" (DPMC, 2018a, p.8). Recognising that there are multiple pathways to wellbeing, the ideas that underpin the seesaw in a park - balancing good stuff with bad stuff, wellbeing as a holistic concept, and the importance of social connections and relationships - could be applied more broadly. The strengths of seesaw model are that children 
globally can easily identify with it, it conveys their ideas in a simple way, and the universal appeal of a seesaw in a park could lend itself to be applied more widely to children outside of the Samoan diaspora.

Secondly, this exploratory research responds to the recommendation by Poulton, Gluckman, Potter, McNaughton, and Lambie (2018) for research that operationalises the multiple determinants of a global concept of wellbeing. Research of this nature can help support multiagency responses to child wellbeing. The Samoan children's holistic definition of wellbeing could lend itself to developing a multi-agency response to child wellbeing. These findings offer valuable insights to the framing of the draft Child and Youth Wellbeing Strategy (DPMC, 2018b); to the Ministry of Pacific Peoples in its work to strengthen the wellbeing of Pasifika; and for consideration by Treasury as part of its Pasifika Living Standards Framework (Thomsen, Tavita, \& Levi-Teu, 2018). These findings could also valuably inform individual sectoral responses to child wellbeing such as the recent nationwide Kōrero Mātauranga / Education Conversation (MoE, 2018), where wellbeing was one of the most frequently mentioned themes.

Thirdly, knowledge of how Samoan children conceptualise their wellbeing and what they consider to be important to their wellbeing has significance for the Samoan diaspora in New Zealand. While the scope of this study was localised to Samoan children living in Wellington, the findings could be relevant to Samoan children living in other parts of New Zealand as well as the wider Pasifika community. This warrants further research. This study supports a counter-narrative to the generalised view about child wellbeing in the Samoan diaspora. For the Samoan diaspora, the knowledge generated in this study increases understanding about Samoan children's conceptions of wellbeing and in turn how wellbeing can be achieved against a shifting landscape. Further, it is hoped that the experience of participation in this study may generate a more robust interest by the Samoan diaspora and Pasifika more broadly, in participating in national policy debates and in the policy-making process.

\section{Conclusion}

This article presents findings from an exploratory study of how 8-year old Samoan living in Wellington conceptualise their wellbeing. Shaped by the paucity of literature that captures the voices of children, particularly the voices of children outside of the mainstream, this is the first study on child wellbeing to privilege the voices of Samoan children. This ethnic-specific study provided an innovative approach to creating the space for Samoan children to share their knowledge and experiences of wellbeing, which could be adapted by other peoples in the diaspora, as appropriate.

Samoan children were able to define what wellbeing means to them and what is important to their wellbeing. Overwhelmingly, the Samoan children saw connecting with loved ones and building relationships as critical to their wellbeing. Through the eyes of 8-year old Samoan children, this study has added new knowledge to the child wellbeing literature. Expanding knowledge and understanding of how children in the Samoan diaspora conceptualise their 
wellbeing is important to the lives of Samoan children now but also for the formulation of policies to shape their future wellbeing.

ANNEX 1: Profiles of the Samoan children and their parents.

\section{THE CHILDREN}
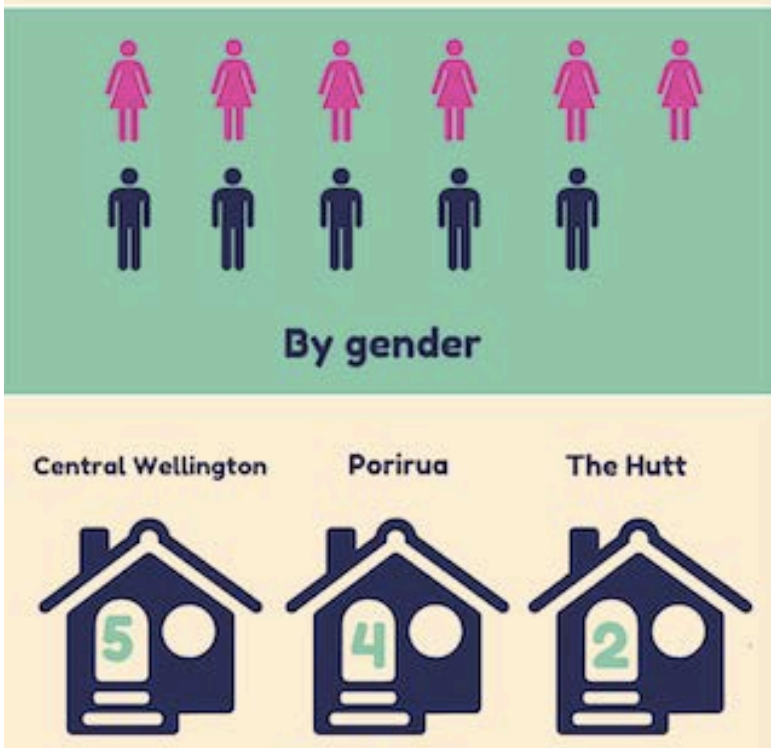

By location
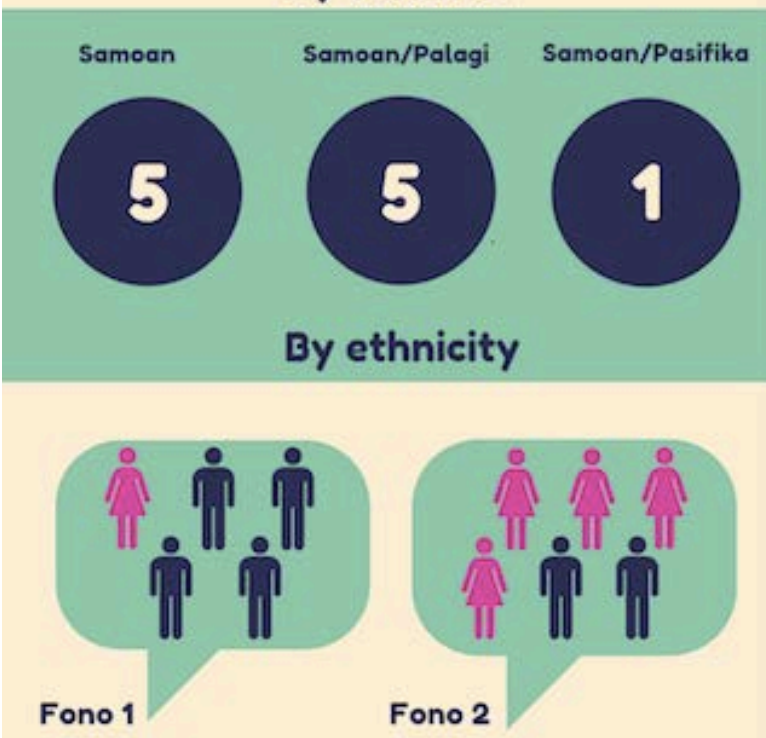

Fono 1

Fono 2

\section{By participation (Fono 1 \& Fono 2)}
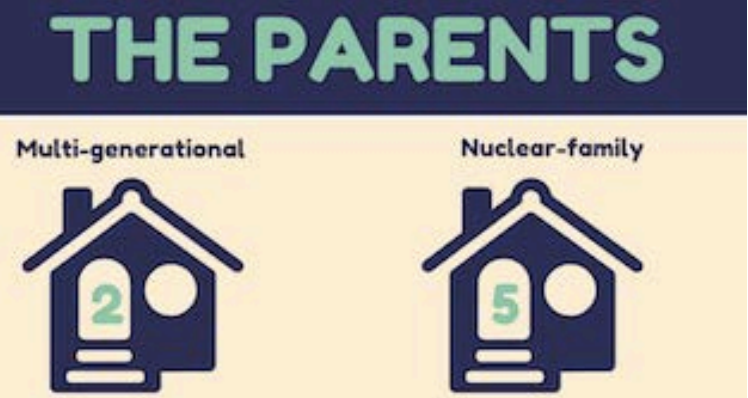

Nuclear-family

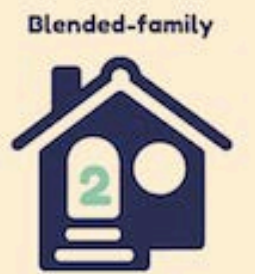

Female-headed

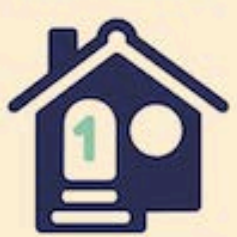

Household composition
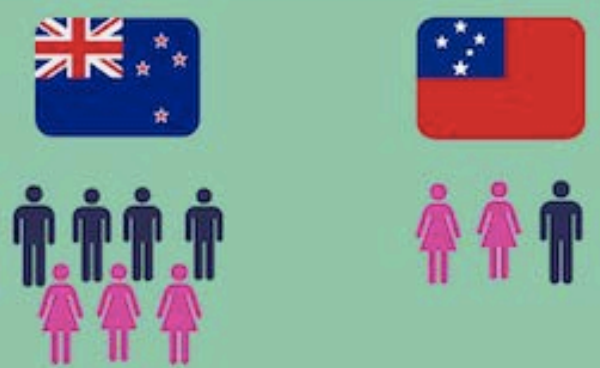

\section{Samoan parent's place of birth}
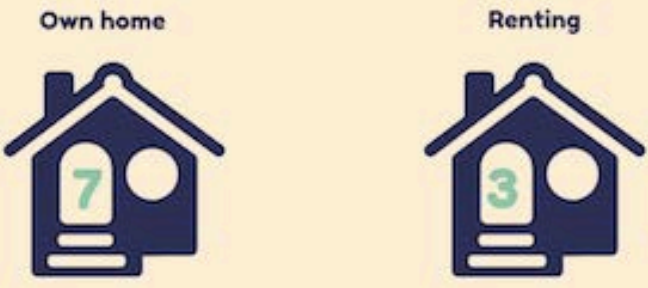

Home ownership

\section{Authors}

Emma Dunlop-Bennett

University of Otago

dunlopbennett@gmail.com

Jenny Bryant-Tokalau

University of Otago 
Anthony Dowell

University of Otago

\section{Publishing Timeline}

Received 14 May 2019

Accepted 23 September 2019

Published 26 September 2019

\section{References}

Amerijckx, G., \& Humblet, P.S. (2014). Child Well-Being: What does it mean? Children \& Society, Volume 28, $404-415$.

Anae, M. (2010). Research for better Pacific Schooling in New Zealand: Teu le va - a Samoan perspective. MAI Review, 1, 1-24.

Anae, M. (2001). The New Vikings of the Sunrise: New Zealand-borns in the Information Age. In C. P. Macpherson., M. Spoonley., \& M, Anae (Eds.), Tangata O Te Moana Nui: Evolving Identities of Pacific Peoples in Aotearoa/New Zealand (pp. 101-122). Palmerston North: Dunmore Press.

Anae, M., Coxon, E., Mara, D., Wendt-Samu, T., \& Finau, C. (2001). Pasifika education research guidelines. A report for the Ministry of Education. Wellington: New Zealand Government.

Ben-Arieh, A. (2000). Beyond welfare: Measuring and monitoring the state of children - New trends and domains. Social Indicators Research, 52 (3), 235-257.

Ben-Arieh, A. (2005). Where are the Children? Children's Role in Measuring and Monitoring their Wellbeing. Social Indicators Research, 74 (3), 573-596.

Ben-Arieh, A. (2008). The Child Indicators Movement: Past, Present and Future. Child Indicators Research, $1(1), 3-16$

Ben-Arieh, A. \& Frønes, I. (2007). Indicators of Children's Well-being: What should be Measured and Why? Social Indicators Research, Vol. 84: 249-250.

Ben-Arieh, A., Ferran, C., Frønes, I., \& Korbin J.E. (2014). Multifaceted Concept of Child Well-Being. In A. Ben-Arieh., C. Ferran., I. Frønes., and J.E Korbin (Eds.), Handbook of Child Well-Being: Theories, Methods and Policies in Global Perspectives (pp.1-27). Dordrecht: Springer Reference.

Berry, J. W. (2006). Contexts of acculturation. In D. L. Sam \& J. W. Berry (Eds.), The Cambridge handbook of acculturation psychology (pp. 27-42). New York: Cambridge University Press.

Bradbury-Jones, C., \& Taylor, J. (2013). Engaging with children as co-researchers: challenges, counterchallenges and solutions. [Online] Available from https://www.research.ed.ac.uk/portal/files/14219275/Taylor 2013 Engaging with children as co researchers.docx.pdf [Accessed 21 July 2016].

Camfield, L., Streuli, N., \& Woodhead, M. (2010). Children's Well-being in Developing Countries: A Conceptual and Methodological Review. European Journal of Development Research, Vol 22 (3), 398416.

Cowley-Malcolm, E. (2013). Perceptions of Samoan Parents from a Small Town in New Zealand on Parenting, Childhood Aggression, and the CD-ROM 'Play Nicely' [unpublished thesis]. Wellington: The University of Victoria.

Cowley-Malcolm, E., Fairbairn-Dunlop, P., Paterson, J., Wanzhen. G., \& Maynard, W. (2009) Child discipline and nurturing practices among a cohort of Pacific mothers living in New Zealand. Pacific Health Dialog, 15(1), 34-46. 
Cronin de Chavez, A., Backett-Milburn, K., Parry, O., \& Platt, S. (2005). Understanding and researching wellbeing: Its usage in different disciplines and potential for health research and health promotion. Health Education Journal, 64 (1), 70-87.

Department of the Prime Minister and Cabinet. (2018a). Child Wellbeing Strategy - Scope and Public Engagement Process. A paper to Cabinet__[Online] Available from https://www.dpmc.govt.nz/sites/default/files/2018-06/Cabinet\%20paperChild\%20Wellbeing\%20Strategy-Scope\%20and\%20Public\%20Engagement\%20ProcessMay\%202018.pdf [Accessed on 27 September 2018].

Department of the Prime Minister and Cabinet. (2018b). Process for Developing the Frist Child Wellbeing Strategy. A paper to Cabinet__[Online] Available from https://www.dpmc.govt.nz/sites/default/files/2018-06/Cabinet\%20paperProcess $\% 20$ for $\% 20$ Developing $\% 20$ the $\% 20$ First $\% 20$ Child $\% 20$ Wellbeing $\% 20$ StrategyJan\%202018.pdf [Accessed on 27 September 2018].

Dunlop-Bennett, E. (2019). Through their eyes: A Samoan perspective on child wellbeing [unpublished thesis]. Dunedin: University of Otago.

Ellard-Gray, A., Jeffrey, N. K., Choubak. M., \& Crann. S.E. (2015). Finding the Hidden Participant: Solutions for Recruiting Hidden, Hard-to-Reach, and Vulnerable Populations. International Journal of Qualitative Methods, Vol 14 (5), 1- 10.

Ereaut, G., \& Whiting, R. (2008). What do we mean by 'wellbeing'? And why might it matter? [Online] Available from http://dera.ioe.ac.uk/8572/1/dcsf-rw073\%20v2.pdf [Accessed 9 January 2018].

Faleolo, M. (2013). Authentication in social work education: The balancing act. In C. Noble., M. Henrickson, \& Y.I. Han (Eds.), Social work education: Voices from the Asia Pacific (pp.105-132). Sydney: Sydney University Press.

Faleolo, M. (2009). Cultural Valid Social Work Education: A Samoan perspective. In C. Noble., M. Henrickson., and Y.I. Han (Eds.), Social Work Education: Voices from the Asia Pacific (pp. 149172). Victoria: The Vulgar Press.

Fa'afoi, A., Parkhill, F., \& Fletcher, J. (2006). Strengthening Pasifika and Palagi research collaboration in Aotearoa research context. In C. Mutch (Ed.), Challenging the notion of 'other': Reframing research in the Aotearoa New Zealand context (pp. 99-118). Wellington: New Zealand Council for Educational Research Press.

Fairbairn-Dunlop, P. \& Coxon., E. (2014) Talanoa: Building a Pasifika Research Culture. Auckland: Dunmore Press.

Fairbairn-Dunlop, P., Nanai, J., \& Ahio, L. (2014). Pacific Research. In V. Wright-St Clair, D. Reid, S. Shaw, \& J. Ramsbotham (Eds.), Evidence-based Health Research (pp. 77-93). Victoria: The Oxford University Press.

Fattore, T., Mason, J., \& Watson, E. (2007). Children's conceptualisation(s) of their well-being. Social Indicators Research 80. Issue 1, 5- 29.

Fattore, T., Mason, J., \& Watson, E. (2009). When children are asked about their well-being: Towards a framework for guiding policy. Child Indicators, 2, 55-77.

Fattore, T., Mason, J., \& Watson, E. (2016). Children's Understandings of Well-Being. Towards a Child Standpoint. Dordrecht: Springer.

Ferguson, P.B., Gorinski, R., Wendt Samu, T. \& Mara, D. (2008). Literature Review on the Experiences of Pacific Learners in the Classroom. A report for the Ministry of Education. Wellington: Ministry of Education.

Frønes, I. (2007). Theorizing Indicators. Social Indicators Research 83, 5- 23. 
Graham, A., Powell, M., Taylor, N., Anderson, D. \& Fitzgerald, R. (2013). Ethical Research Involving Children. A joint initiative by UNICEF, Childwatch International Research, Southern Cross University, \& University of Otago. Florence: UNICEF Innocenti Research Centre.

Heckman, J (2008). The Case for Investing in Disadvantaged Young Children. Big Ideas for Children: Investing in Our Nation's Future. Washington, DC: First Focus.

Larkin, M., \& Thompson, A. (2012). Interpretive phenomenological analysis. In A. Thompson and D. Harper (Eds.), Qualitative research methods in mental health and psychology: a guide for students and practitioners (pp 99-116). Oxford: John Wiley \& Sons.

Larkin, M., S. Watts., \& E. Clifton. (2006). Giving voice and making sense in interpretative phenomenological analysis. Qualitative Research in Psychology, 3 (2), 102-120.

Lilomaiava-Doktor, S. (2009) Beyond "Migration": Samoan Population Movement (Malaga) and the Geography of Social Space (Vā). The Contemporary Pacific, Volume 21 (1), 1-32.

Loto, R., Hodgetts, D., Chamberlain, K., Nikora, L. W., Karapu, R., \& Barnett, A. (2006). Pasifika in the news: e portrayal of Pacific peoples in the press. Journal of Community and Applied Social Psychology, $16,100-118$.

Mageo, J. (1998) Theorizing Self in Samoa: Emotions, Genders, and Sexualities. Michigan: University of Michigan Press.

Macpherson, C. (1997). The Polynesian Diaspora: New Communities and New Questions. In K. Sudo \& S. Yoshida (Eds.), JCAS Symposium Series 3: Contemporary Migration in Oceania: Diaspora and Network (pp. 77-100). Osaka: JCAS.

Macpherson, C. (1996). Pacific Islands identity and community. In P. Spoonley, D. Pearson, \& C. Macpherson (Eds.), Nga Patai: Racism and ethnic relations in Aotearoa/New Zealand (pp. 124-143). Palmerston North: Dunmore Press.

Manolom, T., \& Promphakping, B. (2015). Measuring Well-Being from Local Perspective: The Case of Lao PDR. Social Indicators Research, 123, 391-409.

Marmot, M. (2010). Fair Society, Healthy Lives. The Marmot Review Strategic Review of Health Inequalities in England post-2010. London: University College.

Ministry of Education. (2018). Kōrero Mātauranga IEducation Conversation. [Online] Available from https://conversation.education.govt.nz/ [Accessed on 27 September 2018].

Ministry of Pacific Peoples. (2016). Pacific people in New Zealand. [Online] Available from http://www.mpp.govt.nz/pacific-people-in-nz [Accessed on 10 July 2018].

Naudeau, S., Kataoka, N., Valerio, A., Neuman, M.J., \& Elder L.K. (2011). Investing in Young Children: An Early Childhood Development Guide for Policy Dialogue and Project Preparation. Washington, DC: World Bank.

Neilson, N. (2015). Pacific Way: Auckland's Pasifika community diaspora media. Pacific Journalism Monographs No. 57. Auckland: Pacific Media Centre.

Newman, M., \& Devercelli, A. (2013). What matters most for early childhood development: a framework paper. Washington, DC: World Bank. [Online] Available from https://openknowledge.worldbank.org/handle/10986/20174 [Accessed on 2 December 2015].

New Zealand Child and Youth Epidemiology Service. (2008). The Health of Pacific Children and Young People in New Zealand. Wellington: New Zealand Government.

Office of the Children's Commissioner. (2016). Population, ages and ethnicities of children [Online] Available from http://www.occ.org.nz/assets/Uploads/StatsOnKids/demographics2016.pdf [Accessed on 3 October 2018]

O'Reilly, M., \& Dogra, N. (2017). Interviewing children and young people for research. London: SAGE publications. 
Oxford. (2019). Learner's Dictionaries. [Online] Available from https://www.oxfordlearnersdictionaries.com/definition/english/app [Accessed on 1 August 2019].

Palmer, M., Larkin, M., de Visser, R., \& Fadden. G. (2010). Developing an Interpretative Phenomenological Approach to Focus Group Data. Qualitative Research in Psychology, Vol 7 (2), 99 121.

Pereira, J. (2010). Spare the rod and spoil the child: Samoan perspectives on responsible parenting. Kotuitui: New Zealand Journal of Social Sciences Online, 5(2), 98-109.

Phillips, E., Montague, J., \& Archer, S. (2016). Worlds within worlds: a strategy for using interpretative phenomenological analysis with focus groups. Qualitative Research in Psychology, 13(4), 289-302.

Pollard, E., \& Lee. P. (2003). Child well-being: A systematic review of the Literature. Social Indicators Research, 61, 59-78.

Pool, I., \& Jackson, N. (2017) Population Change [Online] Available from https://teara.govt.nz/en/population-change/print [Accessed on 5 December 2018].

Pouton, R., Gluckman, P., Potter, J., McNaughton, S., \& Lambie, I (2018). Childhood Well-being: What it looks like, how can it be undermined and how to protect and promote it. [Online] Available from https://www.dpmc.govt.nz/sites/default/files/2018-06/Cabinet\%20paper-

Child\%20Wellbeing\%20Strategy-Scope\%20and\%20Public\%20Engagement\%20ProcessMay\%202018.pdf Accessed on 27 September 2018].

Prout, A. \& James, A. (1997). A new paradigm for the sociology of childhood? Provenance, promise and problems. In A. Prout, \& A. James (Eds.), Constructing and Reconstructing Childhood: Contemporary issues in the sociological study of children (pp. 1-28). Routledge: London and New York.

Prout, A., \& James. A. (1990). A new paradigm for the sociology of childhood.' In A. James., and A. Prout (Eds.). Constructing and reconstructing childhood: Contemporary issues in the sociological study of childhood (pp. 7-34). Basingstoke: Falmer Press.

Pulotu-Endermann, K. (1995). Fonofale Model of Health. [Online] Available from http://www.hauora.co.nz/resources/Fonofalemodelexplanation.pdf [Accessed on 1 November 2017].

Saith, A., \& Wazir, R. (2010). Towards Conceptualising Child Wellbeing in India: The Need for a Paradigm Shift. Child Indicators Research, 3; 86-408.

Schoeffel, P., Meleisea, M., David, R., Kalauni, R., Kalolo, K., Kingi, P., \& Williams, S. P. (1996). Pacific Islands Polynesian Attitudes to Child Training and Discipline in New Zealand: Some Policy Implications for Social Welfare and Education. Social Policy. Journal of New Zealand, 6, 134-147.

Seedhouse, D. (1995). Well-being': health promotion's red herring. Health Promotion International. Oxford University Press. Vol. 10 (1), 61-67.

Seiuli, B.M.S. (2012). Uputaua: A therapeutic approach to researching Samoan communities. The Australian Community Psychologist Special Issue - Ignored No Longer: Emerging Indigenous Researchers on Indigenous Psychologies, 24(1), 24-37.

Sixsmith, J., Gabhainn, S.N., Flemming, C., O’Higgins, S. (2007). Children's, parents' and teachers' perceptions of child wellbeing. Health Education, Vol. 107 (6), 511-523.

Smith, J. A., Flowers, P., \& Larkin, M. (2009). Interpretive phenomenological analysis: Theory, research practice. London: Sage Publications.

Statham, J., \& Chase, E. (2010). Childhood wellbeing: A brief overview (Briefing Paper 1). Childhood Wellbeing Research Centre. Loughborough: Loughborough University.

Statistics New Zealand. (2014). Demographics of New Zealand's Pacific Population. [Online] Available from http://www.stats.govt.nz/browse for stats/people and communities/pacific peoples/pacificprogress-demography/population-growth.aspx [Accessed on 27 June 2017]. 
Suaalii-Sauni, T., \& Fulu-Aiolupotea, S. (2014). Decolonising Pacific research, building Pacific research communities and developing Pacific research tools: The case of the talanoa and the faafaletui in Samoa. Asia Pacific Viewpoint, 55(3), 331-344.

Suaalii, T., \& Mavoa, H. (2001). Who says yes? Collective and individual framing of Pacific children's consent to, and participation in, research in New Zealand. Childrenz Issues, 5(1), 39-42.

Taule'ale'ausumai, F.J, (1990) The Word Made Flesh. Dissertation in Pastoral Theology [unpublished thesis]. Dunedin: University of Otago.

Tamasese, K., Peteru, C., Waldegrave, C., \& Bush, A. (2005). Ole Taeao Afua, the new morning: A qualitative investigation into Samoan perspectives on mental health and culturally appropriate services. Australian and New Zealand Journal of Psychiatry, 9(4), 300-309.

Thomsen, S., Tavita, J., \& Levi-Teu, Z. (2018). A Pacific Perspective on the Living Standards Framework and Wellbeing. Available [Online] https://treasury.govt.nz/publications/dp/dp-18-09 [Accessed on 27 September 2018].

Tomkins, L., \& Eatough, V. (2010). Reflecting on the Use of IPA with Focus Groups: Pitfalls and Potentials. Qualitative Research in Psychology, 7, 244-262.

Treasury. (2019). The Wellbeing Budget. [Online] Available from https://treasury.govt.nz/publications/wellbeing-budget/wellbeing-budget-2019-html [Accessed 1 June 2019]

Tui Atua, T.T.E. (2003). In search of Nuance and Metaphor in Social Policy. Social Policy Journal of New Zealand, Issue 20, 49-63.

United Nations General Assembly. (2015). Transforming our world: the 2030 Agenda for Sustainable Development, 21 October 2015, A/RES/70/1, [Online] Available from https://www.refworld.org/docid/57b6e3e44.html [Accessed 22 November 2015].

United Nations General Assembly. (2002). A World Fit for Children. Resolution adopted by the General Assembly. A/RES/S-27/2), United Nations, New York, para 36c: Online] Available from https://www.unicef.org/specialsession/docs new/documents/A-RES-S27-2E.pdf [Accessed 2 December 2015].

United Nations General Assembly. (1989). Convention on the Rights of the Child, 20 November 1989,United Nations, Treaty Series, vol. 1577 [Online] Available from https://www.refworld.org/docid/3ae6b3 [Accessed 22 November 2015].

Vaioleti, T. M. (2013). Talanoa: Differentiating the Talanoa research methodology from phenomenology, narrative, Kaupapa Māori and feminist methodologies. Te Reo, 56 \& 57, 191-212.

Vaioleti, T. (2006). Talanoa Research Methodology. A Developing Position on Pacific Research. The University of Waikato. [Online] Available from http://www.wje.org.nz/index.php/WJE/article/view/296/310 [Accessed on 1 November 2016].

Wang, C., \& Burris. M.A. (1997). Photovoice: Concept, Methodology, and Use for Participatory Needs Assessment. Health Education \& Behaviour. Vol. 24 (3): 369-387.

Weisner, T.S. (2014). Culture, Context, and Child Well-Being. In A. Ben-Arieh, C. Ferran, I. Frønes, \& J.E. Korbin (Eds.), Handbook of Child Well-Being: Theories, Methods and Policies in Global Perspectives (pp. 87-103). Dordrecht: Springer Reference.

White, S. (2009). Bringing Wellbeing into Development Practice. WeD Working Paper 09/50. Wellbeing in Developing Countries Research Group. Bath: University of Bath. 